\title{
Experience and Immersion: Experimental Design of the University Reading Space in Digital Context
}

\author{
Yingxi Huang \\ China Academy of Art \\ Hangzhou, China
}

\begin{abstract}
The place of reading and learning is an important window of spiritual civilization and it is the main platform for contemporary college students to acquire spiritual wealth. With the development of global information, the tide of digitized, networked and mobile informatization technology has broadened the channels for people to obtain and absorb information. From the perspective of human perceptual experience, this paper attempts to explore the possibility of a "humanized" atmosphere of the university reading space under the digital background from three aspects of cognition and emotion, time and space, individual and whole from the viewpoint of psychology and sociology, and puts forward some specific ideas.
\end{abstract}

Keywords-university reading space; design; perceptual; digital; interaction

\section{INTRODUCTION}

Under the background of digitization today, the contemporary college students and teachers have their knowledge structure, awareness level and emotional thoughts increasingly imprinted by the times and changed constantly. Based on the individual feeling and experience, the author puts forward the tentative idea for the innovative service of university reading space under the modern background, and summarizes it from three aspects.

\section{Cognition And EMotion - Perceptual ReAding ATMOSPHERE}

Sensibility is a category of social history that is constantly developing with the change of human' s social practice way. Since Alexander Gottlieb Baumgarten, a philosopher of rationalism in Germany, created the discipline especially for study of human' s perceptual awareness, mankind has begun to explore Sensibility. Asthetik is a discipline that studies human emotional behavior and its regulation. Human perceive the environment through visual, auditory, tactile senses and so on and judge it through their emotional system and then reflect it into their brain, so as to influence individual's thinking and behavior. "People who are the objects of study make activities, survival, recognition and thinking in space, and their feelings always contact and react with the surrounding environment, and further influence each other." ${ }^{1}$ In the research field of university reading space, the factors such as equipment and facilities, resource form, resource position, reading environment and even propaganda logo in the reading places all will affect the individual's feeling, and thus affect students' perceptual practice.

Emotion is inevitable for human beings, and any individual is changing its emotion. Emotion is not judged to be good or bad, whether positive or negative emotions will change the individual way of thinking. According to the research, negative emotions (such as anxiety, fear and other emotions) makes the brain focus on a topic, making a partial emphasis but ignoring the whole, and gradually exploring the problem until some solution is obtained. For the university reading space, we can consider a intensive indoor environment setting of the reading room where we need focus attention to reading (like professional exams, various language exams), such as the use of warm colors, slogans and celebrated dictum, etc., which can help students improve the efficiency of learning. In the reading room of novels, newspapers, periodicals and other leisure resources, the environmental hue, arrangements, flowers can be elegant, natural, relaxed, pleasant, comfortable, so that students feel happy and more creative. Because when the individual is in a positive emotional state (such as gratification, acknowledge, etc.), the brain broadens its processing scope and concentrates on the opportunities offered by positive emotions, with little attention to the specific details, and is more easily adopts to interference and pays attention to a new idea. Positive emotions easily arouse the individual's curiosity, and stimulate their creativity, making the brain become an organism that can carry out a effective learning. "This aesthetic, comfortable simplest, original emotional experience greatly satisfies the individual's emotional appeal, so as to make them naturally feel their value and dignity." ${ }^{2}$

In the era of big data, young people often understand and get access to unknown information through the network; and if the library --- a space of resources collection, provides a guide platform for students in this reading space, making students know the distribution of resources, resource characteristics, space arrangements and reading environment

Luan Dong. Small Discoveries of Sensibility [M]. Beijing: Commercial Press .2007: 3-4.

Qi Peng. Contemporary Culture and Sensibility Revolution [M] Beijing: Culture and Arts Publishing House .2006: 153 
and so on without leaving home, fresh students can quickly enter the virtual reading space and quickly know the arrangements of reading space through the guide; For college students, network guide not only can increase the cordial feeling, but also can help them quickly find the resources they need. The emergence of virtual technology brings opportunities for the construction of reading space in universities, and the immersive experience effect (the real perception of the user in the simulated environment) of the digital network space such as computer, cell phone and Tablet PC, is rapidly changing the perceptual practice way of human. The virtual technology of network has created a media platform for the individual to feel the world and a way of barrier-free communication between the students and the reading atmosphere and of emotional experience for students, which is novel and visualized, with strong sense of experience, being a important emotional bridges between the space and the individual. The revolution of this practical way is also a revolution of the individual's feeling way, thinking way and behavior way.

\section{Time AND Space - Digital Reading Atmosphere}

Today, digital development provides multiple choices for the existence and activity of individuals, which is the extension and sublimation the practical space of reality. Digital reading space is the product of the development of science and technology, fully utilize and develop the advanced information technology and innovate the form of reading. Let science and technology help to spread knowledge, and let knowledge convey the educational service function of reading space. It is the inevitable trend of reading space digitalization construction to adapt to the development of information era. With the popularity and rapid development of mobile electronic terminals, and combined with network virtual technology, it has become a hot topic to expand the panorama in smart phones, tablet devices and other devices. Therefore, it is feasible and meaningful to develop a panoramic navigation and intelligent positioning function of each reading space. By using panoramic navigation and GPS positioning system, individuals can find the required resources through a small mobile terminal and locate it easily to reproduce the reading environment. The system can even help individuals develop fast routes and allow students to familiarize themselves with routes and simulate resources in a virtual network. Using map navigation, students can easily browse each spot in the reading space. The hotspot links can also help to make more detailed information for the resources provided by reading space and save searching time. The panoramic navigation and positioning system can also locate the location of the individual in real time, and make the route and navigation to help the students find the necessary resources. Dynamic images, real feeling, touching and visual effects bring people more convenient, interesting and real psychological experience from the space environment, student query perspective, path and plot.

Time is a digital function. "The new space of digitalized human-machine interface breaks the three-dimensional space with time and location in reality, and opens a heterogeneous space that combines sound, image, and motion at the diversified level at the same time. It has the possibility of infinite space for the preservation, expansion and dissemination of the individual spirit". ${ }^{3}$ The introduction of $3 \mathrm{D}$ virtual reality technology in panoramic navigation and intelligent positioning system can not only enable students to understand the learning environment on their own, and enrich their emotional experience, providing students with a good platform to learn knowledge through reading space. It can also promote real-time propaganda together with portals and WeChat platform, combined with online reading function such as electronic resource system and mobile reading, enabling users to get rid of space and time constraints. At the same time, the combination with functions like related pictures, navigation display and resource query can expand the capacity of information. Individuals can enter a wider information network, and thus resources are shared. It saves the "information space" and gives full play to the educational function of the reading space virtually.

The development of information technology and the popularity of the Internet have brought great opportunities for the development of reading space in university. "The changing of service concept from 'object-oriented' to 'people-oriented' reflects the humanized design values of the reading space in university. It emphasizes the coordination of the individual and the reading space, as well as the spirit and initiative of the individual." " The combination of virtual space and static resources will make the display environment of reading space multidimensional. It can also greatly increase the amount of information and strengthen the interaction between people and resources and reading space.

\section{INDIVIDUAL AND THE WHOLE - INTERACTIVE READING ATMOSPHERE}

Mankind has entered the new perceptual era of audiovisual from the old read-write era. In fact, this new way of feeling is actually adding a new perceptual interface (human - machine) between people and traditional sense objects. On the one hand, the new perceptual platform provides human beings with the speed of light in time and the boundless and vast perceptual interface of globalization in space, and thus giving people the technological means to give full play to subjectivity and creativity. On the other hand, human also create new civilized achievements through new sensory experiences and ways, and the new perceptual culture formed by information and networking, so as to make the cultural thinking of this century enter into a deeper, higher level of reflection and construction.

Reading space in university is the place of knowledge and information collection and spreading for students. Based on the Internet, information resources such as words, pictures, sounds, video and other information resources have been

\footnotetext{
3 Zhang Le. Research on the Application of 3D virtual Network Technology in University Library $[\mathrm{J}]$. Library and Information, 2010,06:76-78

Huang Hai. Research on the Design of Museum 3D Virtual Cultural Relic Display System [J]. Art Panorama, 2012,01:141.
} 
effectively integrated to provide a variety of ways of retrieval and reading. However, university reading space is considered as a cultural information center, so every revolution and innovation in the information field will bring about a change in the behavior pattern of people's life and learning. The traditional two-dimensional information service mode is lack of the feeling being on the scene. The navigation system is limited to the use of computer terminals and cannot meet the needs of the majority of audiences. The digitalization of information resources has greatly developed the function of the smart phone and expanded the organization dimension of the individual and the overall resources. The roaming environment provides the most intuitive form of reading space environment and layout. The construction of digital space can provide a three-dimensional visualized and lively architectural attractions, resource layout, functional division, information introduction, resource query and download environment. "After the using and visiting of a visual library, the user can access to the physical library more conveniently. When people in the virtual world enter the virtual library, he can feel the architectural style and the design of the real library" . ${ }^{5}$ At the same time, students can also decorate and arrange the inside and outside basic settings, and directly reflect his thinking and idea to the staff through network. The high adaptation in intervening environment enables the aesthetic subject to gain full freedom of interaction, feeling and association and improves the experience of the individual in the scene space. The three-dimensional scene is vivid and lively and close to the real scene of campus. At the same time, it can realize query and location function to a certain extent, and fundamentally expand the organizational dimension of human and resources.

\section{CONCLUSION}

Digitalization connects and organizes individuals, and forms an organic whole with the reading space, its resources and the environment; combine the knowledge of natural science, human science, and digital science and so on; and combine individual intelligence with various types of information resources through the information function", 6 and reallocation and utilization according to individual needs, emphasize the differences among subjects and create diversified personalized services, improve the efficiency of resource utilization in reading space, and realize the quasi site and personalized visit. It is worth noting that students with different character are different in their adaptability to the virtual environment, and their learning effects are different. The design of the "interactive" system in the virtual reading space needs to be combined with the characteristics of the people and arouse the curiosity and thirst for knowledge of the individual, so as to improve students' participation and the spreading degree. It is not only conducive to the full use of university reading space, but also to increase the interest of individual reading and the

\footnotetext{
5 Meng Qiong. Research on the Application and Construction of Virtual Library in Second Life [D]. Changchun: Master's Thesis of Northeast Normal University, 2010:18-19

Qi Peng. Contemporary Culture and Sensibility Revolution [M]. Beijing: Culture and Art Publishing House. 2006:239-240
}

cultural atmosphere of the environment, and fully realize the interactivity, diversification, self-service, individualization and innovation of reading space.

\section{REFERENCES}

[1] Luan Dong. Small Discoveries of Sensibility[M]. Beijing: Commercial Press .2007: 3-4.

[2] Qi Peng. Contemporary Culture and Sensibility Revolution [M] Beijing: Culture and Arts Publishing House .2006: 153.

[3] Donald A. Norman, Wang Hongxiang, et al. Emotion@ Design: Why Some Designs You Fall in Love Only by A Glance [M] Taipei: Yuan-Liou Publishing Co.,Ltd., 2011.

[4] Zhang Le. The Application of Network 3D Virtual Technology in University Libraries [J] .Books and Information, 2010,06: 76-78.

[5] Huang Hai. Research on the Design of 3D Virtual Cultural Relics Display System in Museum [J]. Art Grand View, 2012,01: 141.

[6] Meng Qiong. The Application and Construction of Virtual Library in Second Life [D]. Changchun: Northeast Normal University Master's Thesis, 2010: 18-19. 